\title{
SISTEMA CARCELARIO ARGENTINA-BRASIL DESDE UNA PERSPECTIVA DE GÉNERO. CRIMINALIDAD FEMENINA. REGU- LACIÓN INTERNACIONAL
}

Krisstarah Dayane Lobo ${ }^{1}$

Ingrid Y. Rosas Vilarmbia ${ }^{2}$

\section{Introducción}

El presente trabajo es los efectos de desarrollar en forma sucinta uno de los temas fundamentales en nuestro sistema carcelario, el sistema carcelario femenino, además de su vinculación con la consagración de principios internacionales, referido a la regulación en ambos países (Argentina-Brasil), las pautas o directrices de tratamiento en cuanto a la población femenina en las cárceles y sus garantías. A su vez abordar las principales causas de producción de la misma. Dentro del análisis de un sistema federal o de carácter nacional a nivel país a los efectos de brindar un enfoque nacional.

Este trabajo se desarrollara exponiendo en cada título en un primer desarrollo las pautas principales del sistema Argentino y en forma subsiguiente el de Brasil a los efectos de brindar al lector un cotejo para una lectura comparada de ambos sistemas, abarcando en una primera parte directrices internacionales en materia de ejecución penal y en forma posterior desarrollar las leyes que fijan las pautas para la ejecución de penas privativas de libertad; Ley $\mathrm{N}^{\circ} 24460 / 1996$ del sistema argentino y Ley $\mathrm{N}^{\circ} 7210 / 1984$ de Brasil. Para finalizar con una conclusión centrándose específicamente en las causales; se trabaja con datos cuantitativos nacionales de ambos países, referida a la población carcelaria femenina.

En principio como factores que conducen a la criminalidad de la mujer podemos mencionar, los cuales serán profundizados en el presente trabajo, la falta de contención social producto de la no eliminación absoluta de las franjas discriminatorias en base al sexo, además como otra causal se suele mencionar los lazos familiares deteriorados, desarrollo en una familia conflictiva o en zonas marginales, abuso en sus relaciones personales o el caso de familias donde la mujer es el único sostén económico de un hogar de figura paterna ausente .

${ }^{1}$ Estudiante de Derecho de la UFSC de Intercambio en la UNNE por Programa Escala Estudiantes de Grado. Periodo 2016 primer semestre.

${ }^{2}$ Abogada egresada de la Facultad de Derecho y Ciencias Sociales y Políticas. 
En Argentina, el número de mujeres detenidas en cárceles federales aumentó el $193 \%$, mientras que la población masculina creció el 111\% desde el año 1990 hasta el año 2012. ${ }^{3}$ La población absoluta de mujeres encarceladas en el sistema penitenciario brasilero desde 2000 hasta 2014 creció en un $567 \%$, la de la población masculina dio un incremento de $220 \%$, en el mismo periodo.

Se ve sobre la base de lo dicho, un incremento de la actividad delictual por parte de la mujer, a su vez destacar la escasa información relativa a la criminalidad femenina en cuanto a datos y políticas carcelarias, siendo que las mismas gozan de un tratamiento diferenciado respecto a la población masculina, por la situación especial de la mujer verbigracia; embarazo.

\section{Mujeres que cumplen pena privativa de libertad}

Uno de los ítems que ha centrado la atención en las últimas décadas, por la evolución en un contexto globalizado de derechos, es la criminalidad femenina, cuyo tratamiento en el ámbito mundial estuvo delegado, centrándose específicamente tanto los estudios como los datos aportados por la criminalidad, en la criminalidad masculina, es así que en el quinto y sexto congreso de naciones unidas sobre prevención del delito y tratamiento del delincuente 1975 y 1980 se orientó a modificar esta política en búsqueda de respuesta en cuanto al tratamiento de la mujer en el sistema penal, formulando directrices como pautas dentro de la sistemática penal, a su vez de los estudios criminológicos actuales surge que no se puede atribuir la ejecución de un ilícito siguiendo teorías tradicionales como la desviación de la conducta, por ende de un estudio más individual, surge que las mismas obedecen a la anomia, la asociación diferencial y control social. ${ }^{4}$ Los estudios criminológicos contemporáneos atribuyen la criminalidad femenina a la presión social y la desigualdad de género, dando lugar a la teoría de la desigualdad de género, como condicionante y determinante a la comisión de hechos ilícitos (Meda Chesney Lind, 1986). ${ }^{5}$

${ }^{3}$ Centro de Estudios Legales y Sociales (CELS), Ministerio Público de la Defensa de la Nación, Procuración Penitenciaria de la Nación, Mujeres en prisión: Los alcances del castigo, Buenos Aires, Siglo Veintiuno Editores, 2011, p. 27. $420-463$

${ }^{4}$ Sanchez, Mariana, N. (2004). "La mujer en la teoría criminológica". La ventana, No 20. pp.

${ }^{5}$ La teoría de la desigualdad de género, se basan en la existencia de relaciones patriarcales que conducen a formar una desigualdad, empujando a las mujeres a conductas desviadas productos de la victimización, la marginalidad económica y la necesidad de supervivencia. 
La primera institución carcelaria femenina surgió en 1645 en Amsterdam, Holanda, cuya población carcelaria se constituía por mujeres de escasos recursos, alcohólicas, criminales y prostitutas, así a su vez comprendía a aquellas mujeres que se veían privadas de su libertad a los efectos de domesticar, haciendo mención a las mujeres que rompían con los papeles femeninos socialmente construidos.

Las cárceles que permitieron albergar a mujeres separadas de los hombres dentro del sistema penitenciario federal argentino, tienen sus orígenes en 1978, 1992, 1996, 2001 y 2007. También se da la existencia de centros de detención no carcelarios que alojan mujeres detenidas durante periodos prolongados, tal es el caso de gendarmería nacional y prefectura, pero desde 1996 no se han dado la construcción de nuevos alojamientos destinado a albergar a mujeres atendiendo a las necesidades especiales de este grupo. El sistema penitenciario federal Argentino alberga a personas que fueron procesadas y condenadas por tribunales federales frente a la comisión o infracción de leyes federales o comisión de crímenes comunes pero juzgadas por tribunales nacionales. Las cárceles federales Argentinas se dividen teniendo en cuenta la ubicación geográfica; la zona metropolitana que comprende unidades $\mathrm{N}^{\mathrm{o}} 3$ y 31 y el complejo penitenciario federal I (Ezeiza); las unidades No 27 y 21 (Ciudad Autónoma de Buenos Aires), y en el interior del país, $\mathrm{N}^{\circ} 22$ (Jujuy), $\mathrm{N}^{\circ} 23$ (Salta) y $\mathrm{N}^{\circ} 13$ (La Pampa), y los centros de detención de prefectura, gendarmería sobre todos los ubicados en el norte del país, dada la situación que la misma no dispone de la infraestructura necesaria para albergar mujeres dio lugar a numerosos Habeas Corpus pero su presentación generó traslado a otras instalaciones ubicados en lugares transfronterizos lo que tiene como consecuencia la lejanía de sus familiares, provocando un impacto negativo en cuanto a los derechos de las reclusas, tanto reconocidos a nivel nacional como internacional. ${ }^{6}$ No obstante surge la necesidad de actuar frente a situaciones donde hay un menoscabo a la integridad y dignidad humana reconocidos en tratados a los cuales Argentina a adherido, v. gr., Pacto San José de Costa Rica:

En 2005, la interposición de un hábeas corpus por parte de Comisión de Cárceles de la Defensoría General de la Nación y del Defensor oficial, al encontrar en Jujuy 26 mujeres y tres niños de entre 4 y 5 años alojados en un contenedor que tenía una superficie de dos metros por

\footnotetext{
${ }^{6}$ Ministerio Público de la Defensa de la Nación, Procuración Penitenciaria de la Nación. "Mujeres en prisión: los alcances del castigo / compilado por CELS" ${ }^{\prime \prime} 1^{\mathrm{a}}$ ed.- Buenos Aires: Siglo Veintiuno Editores, 2011.pp. 44-46.
} 
diez, con colchones en pésimo estado, un baño improvisado sin agua caliente y una ventana a tres metros de altura, la única entrada de luz y de aire al cerrar las puertas. El hábeas corpus fue resuelto de manera favorable por la Justicia federal, que prohibió los contenedores para el alojamiento de personas detenidas.?

No obstante no se ha dado una respuesta actual en materia de infraestructura que permita un alojamiento más adecuado a la mujer, debido que en algunos casos conlleva a la crianza dentro de los sistemas penitenciarios de menores que necesitan en una primera etapa del acompañamiento continuo natural de la madre por ej.; los primeros meses de vida, además de que la capacidad de alojamiento se ve disminuida por el aumento de la población femenina. Conforme a datos brindados por el SNEEP la población carcelaria femenina en Argentina dentro del año 1990 y año 2007, se dio un crecimiento importante en la tasa de delincuencia femenina que van de 298 a 1039 , lo que implica un crecimiento de $350 \%$, en concordancia con los datos brindados por el sistema federal penitenciario. ${ }^{8}$

\section{mujeres en prisiones federales (Argentina)}

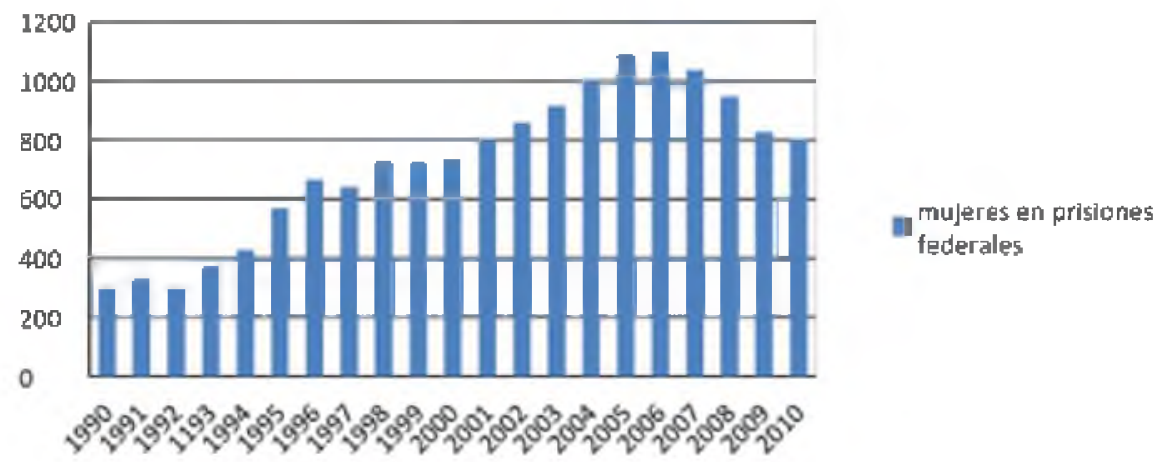
pp. 74-81.

${ }^{7}$ Defensoría General de la Nación, Comisión de Cárceles, "Informe semestral enero/junio 2006",

${ }^{8}$ Informe SNEEP, población carcelaria federal femenina, año 1990 eran de 298; año 1991 de 331; año 1992 de 297; año 1993 de 372; año 1994 de 429; año 1995 de 570; año 1996 de 667; año 1997 de 642; año 1998 de 729; año 1999 de 727; año 2000 de 740; año 2001 de 802; año 2001 de 861; año 2002 de 861; ano 2003 de 918; año 2004 de 1.006; año 2005 de 1.094; año 2006 de 1.105; año 2007 de 1.039; año 2008 de 949; año 2009 de 828; año 2010 de 805. 
Base de datos de SNEEP-Dirección Nacional de Política Criminal, Sistema Nacional de Estadísticas sobre Ejecución de la Pena, Informe Anual Servicio Penitenciario Federal, 2010 y Comisión de Cárceles de la Defensoría General de la Nación, Informe Anual 2010

En el sistema de Brasil la primera norma legal sobre la cárcel femenina fue introducida por el Código Penal de 1940, determinando un establecimiento especial para las presas. En 1937 se dio origen al Instituto Femenino de Readaptación Social, del Río Grande del Sur, 1941 el Presidio de Mujeres, de São Paulo y de 1942 la Penitenciaria Femenina del Distrito Federal, de Bangu.

Sin embargo, la separación entre hombres y mujeres no se realizó con la finalidad de dar más dignidad a la mujer reclusa, pero sí por finalidades distintas en cuanto al instituto de la prisión, esta distinción se hace en base al género, respecto a la población carcelaria masculina era necesario reinstalar el valor del trabajo, en cuanto la población carcelaria femenina es de reinstalar el sentimiento de pudor (Espinoza, 2003, p. 39). Estas instituciones como pautas tenían el de adecuar a las mujeres dentro del ámbito social, prescribiendo conductas ajustadas con el objetivo de reproducir los ideales de las mujeres dignas. La ley de Ejecución Penal (Ley N $\mathrm{N}^{\circ} 7210$, de 11 de julio de 1984) que obliga la separación de establecimientos carcelarios en masculinos y femeninos, actualmente tenemos solamente $7 \%$ son exclusivamente para el público femenino, $17 \%$ (239) aún son mixtos. ${ }^{9}$

La gran parte de los delitos en el ámbito de argentina se encuentra vinculada al tráfico de drogas y estupefacientes, sea por transporte, comercialización o tráfico, no sé de la aplicabilidad atenuada o del principio de proporcionalidad de la pena, lo que se hace frente a estas situaciones es la prisión como medida cautelar, se da la aplicación de carácter restrictivos a la garantías individuales, la población carcelaria femenina se caracteriza por que un $48 \%$ de las que se encuentran privadas de su libertad son extranjeras, y a su vez compuestas por mujeres en mayor parte oscilando entre 30 a 36 años, siendo más longeva que la población masculina.

Las mujeres detenidas tienen 36 años en promedio, dato que confirma la tendencia de una población penitenciaria femenina más longeva que la masculina (Daroqui et al. 2006 y SNEEP 2003). Analizada la edad por grupo etáreo, se encuentra que el $73,6 \%$ de las entrevistadas

\footnotetext{
${ }^{9}$ Levantamiento Nacional de Informaciones Penitenciarias: Infop en Mujeres. Junio de 2014. Departamento Penitenciario Nacional, Ministerio de la Justicia. 2014, p. 15.

${ }^{10}$ Ministerio Público de la Defensa de la Nación, Procuración Penitenciaria de la Nación. "Mujeres en prisión: los alcances del castigo / compilado por CELS" $-1^{\mathrm{a}}$ ed.- Buenos Aires: Siglo Veintiuno Editores, 2011, p. 19 a 30.
} 
es mayor de 30 años; el $41,2 \%$ se concentra en el grupo de 30 a 39 años de edad; el 32,4\% tiene 40 o más años; y sólo el 26,4\% agrupa a mujeres de 18 a 29 años. Si se atiende a la edad de las extranjeras, se observa que el porcentaje más alto $(45 \%)$ se concentra en el rango que va de los 30 a los 39 años de edad, mientras que un $25 \%$ se agrupa en el rango de entre 18 y 29 años, el $17 \%$ tiene entre 40 y 49 , y por último, el $12 \%$ tiene 50 años o más. En este sentido, se observa que la población extranjera femenina también agrupa una franja de mayor edad que la de los hombres. ${ }^{10}$

En el 2014 según datos de SNEEP (sistema nacional sobre ejecución de la pena), encontramos alojadas 735 en contraposición a la población masculina que es 9689, el sistema penitenciario federal envía los datos anualmente al SNEEP a los efectos de realizar estadísticas en cuanto a los sujetos procesados y condenados, pero sólo respecto de aquellos que se encuentran cumpliendo una pena privativa de libertad y el caso de los procesados frente a las restricción de su libertad como medida preventiva. En el ámbito de las mujeres se habla de una situación de un abuso de las medidas preventivas, dentro de esta situación fijando parámetros y a modo de datos generales para observar la presente acotación tenemos un $42,60 \%$ en situación de condena mientras que el $55,14 \%$ se encuentra sin condena firme según informe del año 2009, por parte de la Procuración Penitenciara de la Nación.

Respecto a los datos vinculados a las tipos de penalidades en cuanto a comisión de delitos el mismo se encuentra conformado como mencionamos ut supra, en su gran parte por tráfico de drogas, tal como podemos observar en el gráfico.

\section{Tipos de delitos- Ar}

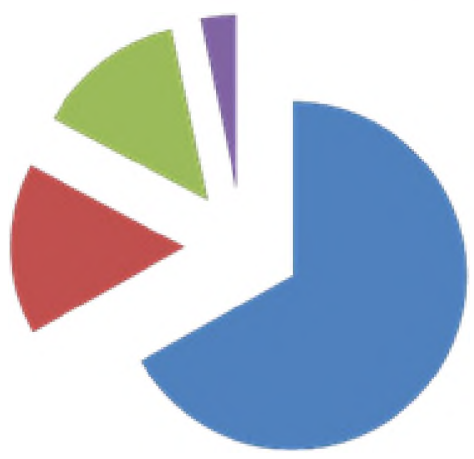

délitos rélacionado a drogas

- telitos contra la propiedad delitos contra otra persona otros delitos 
Informe de la SNEEP y SPF año 2007 , delitos relacionados con drogas $68,20 \% ; 16,20 \%$ delitos contra la propiedad; 14,20 delitos contra las personas; $3,40 \%$ otros delitos.

En Brasil, hubo un crecimiento del $567 \%$ de la población carcelaria femenina, la tasa de aprisionamento ${ }^{11}$ aumentó $460 \%,{ }^{12}$ durante los años de 2000 hasta 2014, como sigue:

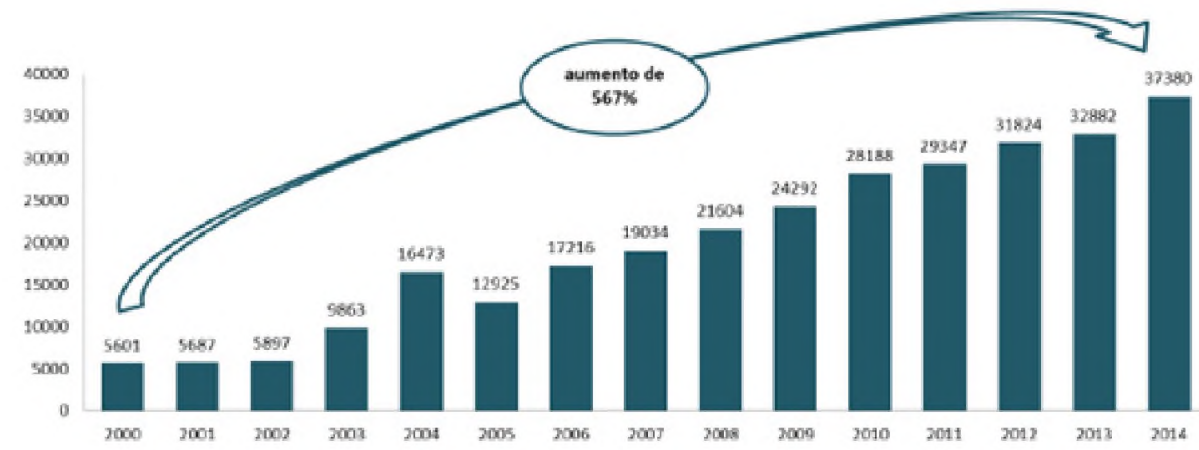

Fuente: Ministerio de la Justicia: a partir de 2005, datos del Infopen/MJ.

Si analizamos el grupo de edad de las reclusas brasileñas vemos que $50 \%$ oscilan en cuanto a edad entre 18 a 29 años, el 50\% de las encarceladas no concluyeron la enseñanza fundamental, en la población carcelaria considerada como uno todo vemos que los números llegan a $68 \%$. En relación a la raza, color u etnia, $68 \%$ de mujeres presas en Brasil son negras. Los datos muestran que, en el sistema penitenciario general (hombres y mujeres), dos de cada tres presos,

${ }^{11}$ La tasa de aprisionamento mide la proporción entre el crecimiento de la población prisional en relación a la población total, en dato periódico.

12 Levantamiento Nacional de Informaciones Penitenciarias: Infop en Mujeres -Junio de 2014. Departamento Penitenciario Nacional, Ministerio de la Justicia.2014, pp. 11, 22 y 24. 
son negros. ${ }^{13}$ El encarcelamiento femenino por tráfico de drogas corresponde a $68 \%$, como muestra el gráfico a seguir:
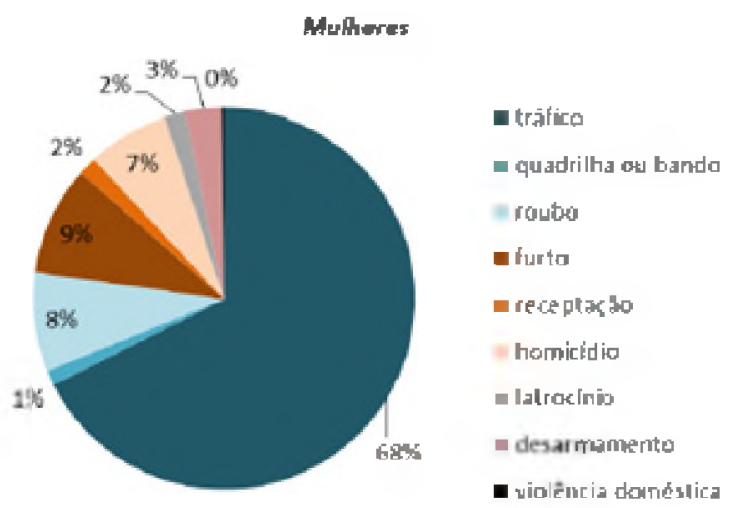

Fuente: Infopen, jun/2014.Departamento Penitenciario Nacional/Ministerio de la Justicia.

Lo que se cuestiona en el sistema de Brasil es que tiende a estigmatizar un grupo específico vinculado a cuestiones raciales siendo que los mismos carecen de políticas estatales que permita su inclusión, es así que debería buscarse reformar los parámetros de políticas públicas y buscar una inclusión global sin parámetros de discriminación racial cercenando a un grupo étnico.

\section{La etapa de Ejecución penal. Tipos de pena. Legislación internacional, reglas para el tratamiento de las reclusas y medidas no privativas de libertad para mujeres delincuentes (reglas de Bangkok)}

Es necesario comprender cómo se da la aplicación de las penalidades para llegar al aspecto de los sistemas carcelarios, asimismo el ámbito del sistema del código penal y comprender mejor el desarrollo del sistema penitenciario dentro de las etapas de criminalidad. El establecimiento de sanciones penales se hará

${ }^{13}$ Levantamiento Nacional de Informaciones Penitenciarias: Infop en Mujeres -Junio de 2014. Departamento Penitenciario Nacional, Ministerio de la Justicia. 2014. 
efectivo respecto de una persona, cuando se de la existencia de un procedimiento previo que culmina con una sentencia condenatoria, dicho procedimiento se encuentra legislado en nuestro ámbito por el código procesal penal, dando lugar a la conocida etapa de ejecución penal.

En Argentina el sistema procesal penal actual regente es un sistema mixto, empero se dio el surgimiento de un código procesal con adopción de un sistema acusatorio el cual se encuentra sancionado y aprobado año 2015, no obstante está pendiente de incorporación al ámbito territorial argentino en cuanto su aspecto fáctico. Dentro del régimen legal argentino se reconocen las siguientes penalidades conforme art. 5 del C.P., reclusión, prisión, multa e inhabilitación. En materia de ejecución penal, el juez que tiene competencia para tener conocimiento respecto del mismo es el juez de ejecución, estableciéndose pautas en cuanto a la ejecución de la pena en el art. 243 CPP:

El juez de ejecución tendrá competencia para:

1) Controlar que se respeten todas las garantías constitucionales y tratados internacionales ratificados por la República Argentina, en el trato otorgado a los condenados, presos y personas sometidas a medidas de seguridad.

2) Controlar el cumplimiento por parte del imputado de las instrucciones e imposiciones establecidas en la caso de suspensión del procedimiento a prueba

3) Controlar el cumplimiento efectivo de las sentencias en condenas dictadas por el poder judicial de la Nación

4) Resolver todos los incidentes que se susciten en dicho periodo.

5) Colaborar con la reinserción social de los liberados condicionalmente.

El proceso penal brasilero también es clasificado como mixto o sea, inquisitorio en el interrogatorio judicial y acusatorio (juez-espectador) en la fase procesal, sin embargo, grandes penalistas defienden la idea de la fase procesal no es acusatoria, pero sí inquisitorial, pues al juez es permitido actos típicamente de la parte acusadora (juez-actor) ${ }^{14}$ así, pensamos que el sistema procesal penal es esencialmente inquisitivo.

${ }^{14}$ El procesalista penal Aury Lopes Júnior (2015. p. 45) critica vehementemente la clasificación de un sistema procesal penal mixto. Para el penalista "(...) de nada sirve la separación inicial de las funciones si después se permite que el juez tenga iniciativa probatoria, determine de oficio la recolección de pruebas (art. 156), decrete de oficio la prisión preventiva, o aún condene delante del pedido de absolución del Ministerio Público (problemática del art. 385)". 
La Carta Magna de Brasil establece parámetros en el art. $5^{\circ}$ inc. L a seguir en cuanto al tratamiento de las mujeres embarazada, para brindar la posibilidad de poder amamantar, en el mismo sentido, la reforma más reciente referente la ejecución en materia de pena relacionada a la mujer fue sancionada por la Ley $\mathrm{N}^{\circ} 11942 / 2009$, alterando los artículos $14,83 \S 2^{\circ}$ y 89 da ley de ejecución penal brasilera (Ley $\left.N^{\circ} 7210 / 1984\right)$ garantizando nuevos derechos las presas embarazadas y con hijos pequeños:

Artículo $14 \xi 3^{\circ}$ Será asegurado el acompañamiento médico a la mujer, principalmente en el prenatal y en el pos-parto, extensivo al recién nacido.

Articulo $83 \S 2^{\circ}$ Los establecimientos penales destinados la mujeres serán dotados de espacios aptos para menores, donde las condenadas puedan cuidar de sus hijos, inclusive amamantarlos, en un mínimo, hasta 6 (seis) meses de edad.

Articulo 89 (...) la penitenciaria de mujeres será dotada de sección para menores no inferiores a seis meses y hasta siete años, aptos para que pueda convivir un menor a los efectos de no afectar el vínculo familiar con la madre

Artículo 117 Solamente se admitirá la aplicación del beneficio de régimen abierto en residencia particular cuando tratarse de:

III. condenada con hijo más pequeño o deficiente físico o mental;

IV. condenada gestante.

El artículo XLII (artículo 5 de CRFB) establece que "la pena se cumplirá en establecimientos distintos (...) de acuerdo con el sexo del penado" en el mismo sentido el Código Penal en el artículo 37 establece que "Las mujeres cumplen pena en establecimiento propio, observándose los deberes y derechos inherentes a su condición personal", también la LEP en el artículo $82 \& 1^{\circ}$ "La mujer y el mayor de sesenta años, separadamente, en un establecimiento propio y adecuado a la su condición personal". Es importante resaltar que "establecimiento distinguido" y "establecimiento propio" no dice respecto a otro pabellón, pero sí a toda una infraestructura adaptada para las mujeres (Castilho, 2007).

El artículo 19 de la Ley de Ejecución Penal, que sigue: "La enseñanza profesional será suministrado en nivel de iniciación o de perfeccionamiento técnico. Párrafo único: La mujer condenada tendrá enseñanza profesional adecuado a su 
condición". Esta última parte sugiere que hay profesiones no adecuadas para las mujeres, conclusión que debe ser rechazado pues remite la herencia de una sociedad patriarcal que restringe históricamente la mujer del espacio público y de importantes cargos, además, cada vez más mujeres viene ocupando con éxito cargos típicamente masculinos.

La cárcel femenina debe estar compuesta prioritariamente por profesionales mujeres, como consta en el artículo $77 . \S 2^{\circ}$ de la LEP: "En el establecimiento para mujeres solamente se permitirá el trabajo de personal del sexo femenino, salvo cuando se trate de personal técnico especializado". Avena $(2014$, p. 173) "Por exclusión, se establece que deberá ser del sexo femenino el personal administrativo, de instrucción, técnica y vigilancia".

A partir del año 2010 en el ámbito de la ONU, se aprobó las reglas para el tratamiento de las reclusas y medidas no privativas de libertad conocidas como las reglas de Bangkok, a través de unas 70 reglas brindan pautas para un tratamiento diferenciado en la mujer pero basados en leyes y políticas sensibles al género. El surgimiento de las presentes disposiciones se da como respuesta a la falta de políticas referidas a la ejecución de la pena en mujeres como política de género, la misma tienen un carácter complementario a las reglas de Tokio, el trato diferenciado se basa en que la mujer presenta situaciones diferentes a lo de los hombres; verbigracia el estado de embarazo en la ejecución de una pena privativa de libertad. La regla $\mathrm{N}^{\circ} 57$ nos brinda pautas para aplicación de penas que no conllevan a la privación o restricción a la libertad; estableciendo que toda ejecución o efectivización de la pena tiene que tomarse a consideración la situación de la mujer procurando evitar se acrecenté su grado de victimización y procurar la conservación de sus lazos familiares, ídem a los parámetros prefijados a las reglas de Tokio, también establece la posibilidad de que frente a la comisión de determinados delitos en lo que fuere posible se dé la utilización de mecanismos alternativos a la prisión, la regla 61 habla de causales de atenuación de la pena a los efectos de evitar la prisión, tal el caso de los antecedentes penales, la ausencia de los mismos; la levedad del delito como también el carácter del comportamiento delictivo. La regla 60 nos habla de los recursos que debe disponer la mujer no sólo a los efectos de la reinserción si no como medios para coadyuvar en el caso que fueren víctimas de violencia o hayan padecido alguna clase de abuso dentro de su ámbito o círculo cercano. 


\section{La pena privativa de libertad, la prisión y condiciones de ejecución de la pena en la mujer}

La Ley $\mathrm{N}^{\circ} 24660$ regula lo que comprende ejecución de una pena privativa de libertad. El marco regulatorio de dicha ley argentina contiene entre pautas regulatorias los derechos y garantías que ha de revestir dicha aprehensión. Mencionaremos los parámetros principales de dicha ley, como finalidad marco la ley establece la finalidad de reinserción social y la adecuación legal de su conducta, siendo que la misma expresa que se persigue a que el infractor adquiera capacidad de comprensión y respeto al marco legal al que se haya circunscripto y al cual alteró con su conducta desviada. Dentro del lapso de ejecución de la pena podrá ejercer los derechos que no se haya privado como consecuencia de producción del ilícito. La ejecución de su condena está sometida a control judicial permanente.

En relación a los principios rectores tenemos como parámetro, la igualdad en la aplicación de las normas de ejecución, a su vez está exento de tratos crueles e inhumanos, se reconoce la característica de progresividad del régimen penitenciario, el mismo consta de cuatro períodos; el de observación a los efectos de recabar la información necesaria del condenado, para su adecuado tratamiento; el periodo de tratamiento que puede comprender medidas que impliquen una atenuación de las restricciones; el periodo de prueba que comprende incorporación en establecimientos más abiertos, salidas transitorias y semilibertad; y finalmente las salidas transitorias que su duración depende del hecho que la fundamenta, por el periodo acordado y la confianza que se adopte, también comprende libertad condicional previo cumplimiento de las condiciones prefijadas en el código procesal y los respectivos informes que detallan antecedentes de conducta, conceptos y dictamen criminológico desde el comienzo de ejecución de la pena acompañado de un programa de prelibertad que procurará la preparación para su actuación en la vida libre.

El sistema argentino presenta alternativas a la prisión; la prisión domiciliaria, aplicable a las personas mayores de 60 años o con enfermedad incurable en tratamiento terminal, la prisión discontinua, por lapsos no menores a $36 \mathrm{hs}$ procurando no perjudicar los días laborables y el régimen de semidetención, que comprende la prisión diurna permanencia diaria entre las ocho y dieciséis horas, la prisión nocturna permanencia diaria entre las veintiuna y seis de la mañana. Esta podrá ser sustituida previo acuerdo con el juez de trabajos comunitarios no remunerados. 
Los derechos que se encuentran enumerados en la presente ley se puede mentar en rasgos generales, la denominación (identidad por su nombre en respeto a su derecho personalísimo de identificación e individualidad); higiene; alojamiento; vestimenta y ropa, de acuerdo al clima de la estación; alimentación informes y peticiones, información en cuanto al régimen al que se encuentra sujeto y régimen disciplinario; tenencia y depósitos de valores que el condenado llevare consigo o que recibiera con posterioridad y que no pudiere retener consigo se recepcionará en la unidad respectiva previo inventario y traslado del interno, se debe realizar deben ser realizados exentos de publicidad y bajo condiciones de higiene y seguridad. Los mismos serán desarrollados con mayor énfasis en las reglas de Bangkok.

La Legislación Brasilera consagra tres tipos de pena: la pena privativa de libertad, restrictiva de derecho y multa. ${ }^{15}$ Por su parte, la Ejecución Penal disciplina el cumplimiento de la sentencia penal y sus objetivos, ${ }^{16}$ o sea, pretende disciplinar el poder de punir del Estado y reintegrar el individuo socialmente.

En materia de regulación internacional el artículo 10 del Pacto Internacional de Derechos Civiles y Políticos y la Regla $\mathrm{N}^{\circ} 8$ de las Reglas Mínimas, los procesados deben estar separados de los condenados y deben ser tratados de acuerdo con su condición de personas no condenadas por la comisión de un delito; en cuanto a regulación del grupo femenino privado de libertad encontramos las reglas de Bangkok; el principio general fijado en la regla 1, es la búsqueda de un tratamiento igualitario a las reclusas pero sujetas a las condiciones especiales de las reclusas.

En cuanto a su ingreso, evaluación y calificación, debe brindarse información y asesoría al momento del ingreso y recabar información sobre sus hijos/ as, el lugar de reclusión debe ser cercano a su lugar de residencia, ${ }^{17}$ para evitar

${ }^{15}$ Art. 32 CP brasilero.

${ }^{16}$ En Argentina está presente en el artículo $1^{\circ}$ da Ley $N^{\circ}$ 24660/1996: La ejecución de la pena privativa de libertad, en todas sus modalidades, tiene por finalidad lograr que el condenado adquiera la capacidad de comprender y respetar la ley procurando su adecuada reinserción social, promoviendo la comprensión y el apoyo de la sociedad. El régimen penitenciario deberá utilizar, de acuerdo con las circunstancias de cada caso, todos los medios de tratamiento interdisciplinario que resulten apropiados para la finalidad enunciada, en Brasil $\mathrm{N}^{0} 7210$ de 11 de julio de 1984, art. $1^{0}$ "la ejecución penal tiene por objetivo efectivizar las disposiciones de la sentencia o decisión criminal y proporcionar condiciones para la armónica integración social del condenado o del internado".

${ }^{17}$ Población Carcelaria (53,71\%) se encontraban detenidas a una distancia mayor a $100 \mathrm{~km}$ de su hogar y familia. Del $46,29 \%$ de las mujeres encarceladas a una distancia inferior a $100 \mathrm{~km}$, el $86,46 \% \mathrm{se}$ encontraba, al menos, a $30 \mathrm{~km}$ de distancia de sus hogares. (Datos derivados de una encuesta nacional de la población carcelaria femenina realizada la Fundación Avon para las Mujeres ("Avon Foundation for Women") y la Facultad de Derecho de la Universidad de Chicago. 
el desarraigo y que la pena trascienda a terceros, los criterios de clasificación y la evaluación del riesgo deben responder a las necesidades particulares y la aplicación de una perspectiva de género, además debe darse lugar a políticas de intervención que permita su reincorporación a la vida en libertad.

La asistencia médica adecuada que comprende amén de la atención a la salud sexual y reproductiva, es necesario abordar desde la perspectiva de género la atención a la salud mental, abuso de drogas y el tratamiento, la atención de otras enfermedades, como por ejemplo VIH, acceso a los servicios de salud preventiva, como la detección del cáncer de mama, ${ }^{18}$ todo tratamiento conlleva la obligación del respeto a su dignidad. Asimismo se debe brindar protección contra cualquier forma de violencia como ser la prohibición del aislamiento y del contacto familiar como sanciones para mujeres embarazadas o madres, ser supervisadas por personal femenino y capacitado especialmente existiendo una prohibición del uso de medios de coerción durante el trabajo de parto, parto y post-parto.

En materia de higiene, las Reglas $\mathrm{N}^{\circ} 10$ a 14 de las Reglas Mínimas establecen que los lugares destinados al alojamiento deben mantenerse limpios y en buen estado, satisfacer las necesidades de higiene y las instalaciones sanitarias y de baño deben ser adecuada cumpliendo parámetros tantos nacionales como internacionales, si bien del análisis de los datos de trabajos de sondeo de campos brindado por el CELS se determina que en su mayoría se cumple con los estándares prefijados en cuanto a infraestructura, respecto al mantenimiento de estas instalaciones, en el mismo se destacó la precariedad de su mantenimiento para brindar un lugar saludable a las reclusas. Toda estancia debe complementarse con programas de trabajo y educación para favorecer su reinserción a la vida en comunidad.

Los programas de cohabitación de menores con sus madres deben cumplir con pautas esenciales como, asegurar las necesidades de los niños y niñas que viven con sus madres en prisión, dando cumplimiento al principio del interés superior del niño. En Argentina su legislación permite a la madre optar por ejercer

${ }^{18}$ Respecto a los chequeos especificos para mujeres, el $43.2 \%$ de ellas afirma que en el último año no le han realizado el papanicolau y al $61 \%$ de las mujeres mayores de 35 años no le practicaron la mamografía. el $62 \%$ de las mujeres a las que sí les practicaron los chequeos antes referidos, no les informaron los resultados, al $35 \%$ de las mujeres que solicitaron algún método anticonceptivo, le fue denegado (conforme datos de la investigación llevado a cabo por CELS, centros de estudios legales y sociales año 2011). 
su patria potestad dentro del sistema carcelario en menores de hasta 4 años. ${ }^{19} \mathrm{Ar}-$ gentina en al año 2009 adoptó una ley que permite la prisión domiciliaria respecto de aquellas mujeres que tienen hijos menores a 5 años o hijos discapacitados (Ley No 26472), rige también respecto de mujeres embarazadas. ${ }^{20}$

\section{Causas que favorecen la criminalidad femenina}

Tal como se pudo observar en los gráficos en el sistema penitenciario federal Argentino se alberga a mujeres que en su mayoría se encuentran privadas de su libertad por crímenes vinculados al tráfico de drogas, cabe destacar que se da un uso desviado del instituto de prisión como medida cautelar frente a delitos vinculados a drogas, como la gravedad irrisoria. La Comisión Interamericana de Derechos Humanos, en el informe de Fondo, Informe No 2/97, del 11 de marzo de 1997, destacó la preocupación respecto a la cantidad de detenidos sujetos al régimen de prisión preventiva en las prisiones argentinas en cotejo con los condenados. Partiendo del conocimiento generalizado que la mayoría de las mujeres privadas de libertad, proviene de un grupo marginado tanto social como económicamente, perteneciendo a un grupo en situación de pobreza o que han sido víctimas de un continuo abuso y constantemente resultado de la violencia ejercida sobre las mismas. De los siguientes datos podemos deducir que determinados delitos son cometido en respuestas a las necesidades insatisfechas o la necesidad económica o la de protección frente a parejas abusivas o relaciones de carácter violento cometidos contra las mismas, el $55,75 \%$ habían sido procesadas o condenadas por tráfico de estupefacientes el 20,8\% se encontraba privada de la libertad por robo, siendo la misma una respuesta frente a las necesidades económicas por encontrarse en situación de pobreza o marginalidad o por la obligación al ser el único sostén de su hogar al no poderse incorporar al mercado laboral por la escasa preparación educativa, el $10,18 \%$ por homicidio (de las cuales el $22 \%$ estaba imputada o condenada por matar a su pareja o cónyuge), y el 1,33\% por lesiones (de las cuales cerca del $33 \%$ estaba imputada o condenada por atacar a

${ }^{19}$ Fuera de los pabellones, hay una guardería que está bien equipada con juguetes, un lugar de juegos y personal de tiempo completo para cuidar a los niños mientras sus madres trabajan en la prisión. Los funcionarios de la prisión nos indicaron que los pañales, la fórmula infantil y la comida eran provistos por la prisión, pero que las madres debían proporcionar la ropa para sus hijos. Más del 84\% de las mujeres indicó que su hijo sólo recibe una comida al día y que los niños podrían comer mejor fuera de la prisión. (Datos conforme a encuesta sobre Programa de Cohabitación).

${ }^{20}$ Arts. 1 y 4 de la Ley N 26.472 de 2009 (modificaron el art. 32 de la Ley No 24660 y el art. 10 del Código Penal, respectivamente, para permitir el arresto domiciliario en el caso de una mujer embarazada o una madre de un niño menor de cinco años de edad o de una persona con discapacidad a su cargo). 
su pareja o cónyuge), como respuesta a la presión y dominación ejercida sobre su persona y como consecuencia del constante abuso físico y mental. El 11,94\% restante informó que se encontraba en prisión por "otros" delitos, que incluían contrabando o tentativa de contrabando, falsificación, secuestro y formas modernas de esclavitud. Es dable observar que la mayoría de los crímenes cometidos fueron de características no violentas, detentando que obedece a una estratificación social inadecuada y como manifestación de la marginalización económica sufrida o la falta de respuestas del Estado relativos a políticas que favorezcan disminuir la brecha, permitiendo el acceso a mejores condiciones de trabajos o al menos a trabajo alguno, para dar respuestas a las necesidades circundantes que motiva la comisión de un hecho ilícito. Se suele atribuir el aumento de actividad delictivo por el cambio social experimentado en el año 1990 que conllevo crisis económicas produciendo empobrecimiento y desocupación lo que produjo un impacto, y concordantes con la etapa de cambios en la estructura familiar, donde la mujer pasó a ocupar un rol fundamental en muchos casos como jefa de familia y único sostén, por ende la presión de afrontar las responsabilidad frente a sus hijos menores, las tareas del hogar y la de obtener recursos económicos para hacer frente a dichas responsabilidades. Autores como Allan (1996) sostienen que para que la mujer se incorpore a una vida delictiva en general necesitan de una provocación suficiente a la de los hombres, dado que la naturaleza de la mujer no es de carácter delictivo, ${ }^{21}$ por ende su respuesta es más condicionante.

En materia de tráfico de drogas elemento mayormente presente como actividad delictiva de las mujeres se puede clasificar en tres categorías; el primero vinculado a los cometidos por propia voluntad en coparticipación activa por el vínculo preexistente con el hombre; el segundo integrado por aquellas mujeres que cometen ilícitos obligadas por una relación de abuso preexistente; el tercer grupo que se produce frente a una necesidad de supervivencia y como única vía para el sostén de su grupo familiar de un grupo donde es la única responsable económica.

En Brasil como se puede observar en los gráficos, los datos son reveladores al trazar el perfil de la mujer delincuente brasilera: (68\%) son mujeres negras, $(50 \%)$ jóvenes, que no concluyeron la enseñanza fundamental $(50 \%)$, siendo

${ }^{21}$ Las mujeres necesitan un estímulo más fuerte y poderoso que los hombres para cometer delitos. Esto puede vincularse a una socialización que incluye controles internos más fuertes que producen mayor supervisión y control sobre las mujeres, lo que reduce riesgos y oportunidades en las elecciones desviantes femeninas. 
prendidas por tráfico de drogas $(68 \%)$.En esas estadísticas, queda explícito la exclusión social de un grupo marginalizado.

El tema de la criminalidad femenina es complejo, se relaciona en un contexto de una sociedad profundamente patriarcal y capitalista, con dinámica de factores de orden cultural, social y económica. Por lo tanto, a partir de la perspectiva del lugar ocupado socialmente por las mujeres, la comprensión de la criminalidad femenina debe necesariamente envolver un nivel más amplio de análisis, que incluya el papel ejercido por el control y por la opresión sobre las mujeres en diferentes esferas, del espacio privado de las relaciones familiares al espacio público de la división del trabajo (Heidensohn, 1993).

Los históricos engranajes creados en torno a la criminalización de las drogas viene abriendo el abanico para el aprisionamiento de mujeres, el resultado es que sobre las mujeres se da el mismo efecto que respecto a la población masculina, acaban (aunque no siempre por los mismos motivos) seducidas para ese comercio.

La existencia de violencia es un motivo determinante y necesario de analizar, por ende los tratados internacionales vinculados a la protección de la mujer con una perspectiva de género no desconoce la existencia de altos índices de violencia contra la mujer; tal es el caso de las Reglas de Bangkok también reconocen "que el número de reclusas que han sido víctimas de violencia en el hogar es desproporcionado". El 39,04\% han experimentado violencia de parte de una pareja o un miembro de su familia antes de ser encarceladas, mientras que el $13,6 \%$ había sido violada al menos una vez antes de ser privada de la libertad. ${ }^{22}$

El crecimiento de la participación femenina en el mercado de trabajo brasilero a partir de los años $70,{ }^{23}$ redefinió los patrones de comportamiento y los valores relativos al papel social de la mujer. La mujer en el espacio público pasa a ser también fuente del presupuesto doméstico, en 2010 las familias a cargo de mujeres como cabeza de familia representan $38,7 \%$ de los domicilios brasileños, ${ }^{24}$ o sea, cada 10 familias brasileñas, 4 son sostenidas por mujeres.

${ }^{22}$ Cornell Law School's Avon Global Center for Women and Justice and International Human Rights Clinic; Defensoría General de la Nación de la República Argentina; The University of Chicago Law School International; Human Rights Clinic; "mujeres en prisión en Argentina: condiciones, causas y consecuencias". Mayo 2013.

${ }^{23}$ Brasil en la década de 70 estaba delante de una verdadera expansión en la economía, creciente urbanización e industrialización, además de la elevación de las expectativas de consumo unidos a estos factores, los movimientos feministas predicaban la emancipación de la mujer y la búsqueda por sus derechos.

${ }^{24}$ Segundo IBGE 2010. 
La responsabilidad por el sostenimiento de la familia en Brasil obedece a las mismas causales que en gran parte de los países latinoamericanos, funcionando como factor social determinante el cambio de roles sociales, colocando a la mujer como única responsable de su grupo familiar, frente a un sistema que somete a trabajadores a condiciones precarizadas de trabajo, con un salario básico de bajas expectativas, que no contribuye o compensa las necesidades de la familia de forma completa, colaborando a buscar como medio recurrir al mercado ilícito del tráfico de drogas, siendo usada como una técnica de supervivencia, frente a un sistema capitalista que favorece el consumo incentivado por la economía neoliberal.

Sin embargo, no solamente el factor económico es determinante en la trayectoria criminal femenina. Es evidente que el poder económico está conectado al crimen, pero no podemos confundir pobreza con crimen, lo que nos llevaría a caer en el reduccionismo de las relaciones sociales, que nada nos sirve. Hay factores culturales íntimamente ligados en la sociedad patriarcal que, asociado la pobreza o no, contribuye para que la mujer derive en una actitud delictual. Excluidas de un sistema social que no reconoce su existencia, ${ }^{25}$ las jóvenes buscan una estrategia de fuga de la invisibilidad social, y encuentran en la red de drogas el sentimiento de pertenencia a un grupo. Tratándose de la participación femenina hay que considerar aspectos peculiares, pues, ingresando en un ramo de trabajo típicamente masculino, las mujeres buscan el ingreso para distinguirse de las otras mujeres a su alrededor, la búsqueda por el status de la mujer peligrosa y poderosa ${ }^{26}$ es la promesa que irán a hacerlas visibles.

Ocurre que, los valores de la sociedad patriarcal también se reproducen en la jerarquía del tráfico. Mayoritariamente, las mujeres (así como los niños de la comunidad) ocupan funciones subsidiarias o subalternas como "mula", "vapor" "fogueteira", muchas son "caja", "vendedora" o aún, "dueña de la boca". 27

${ }^{25}$ La falta de representatividad de la mujer negra tanto en el círculo social, como en los productos y en el mercado de trabajo formal ocupando altos cargos, por ejemplo.

${ }^{26}$ Mariana Barcinski en su artículo "Mujeres en el tráfico de drogas: la criminalidad como estrategia de salida de la invisibilidad social femenina" entrevista Vanessa (nombre ficticio) que posee implicación en el tráfico de drogas carioca, en oportunidad dice: "Eu também gostava do respeito, tudo. Pô, eu chegava, era legal assim eu ir no baile aí, caramba, o baile cheiầo, um montâo de vagabunda andando e eu lá no meio. Caraca, todo mundo parava pra olhar (risos da entrevistadora). Caraca, aí só ouvia cochichando: caraca, olha aquela garota".

${ }^{27} \mathrm{~L}$ a expresión "mula" o "avión" dice respeto la persona que transporta la droga, "vapor" a que negocia pequeñas cantidades en el varejo y "fogueteira" es quien controla la presencia de la policía. 
Además, tales mujeres externamente están más expuestas la acción policial y por no conseguir un alto logro con el tráfico (por el papel secundario en el crimen), no consiguen negociar su libertad (con los policías o pagando un abogado), quedando más vulnerables a la aplicación de la prisión.

Las relaciones afectivas heterosexuales también permiten las particularidades de la delincuencia femenina, a partir de la idealización del amor romántico, ${ }^{28}$ la mujer se envuelve en el tráfico de drogas por el deber de fidelidad y lealtad al compañero que ya se encuentra vinculado, o sea "la mujer del bandido" debe atender las necesidades del compañero encarcelado sometida a los códigos informales de las relaciones hetero-normativas. Argumenta (Zaluar, 1993, p. 181) que "La mujer verdadera del bandido es aquella que, junto con la madre y las hermanas, lo ayuda en la hora del sofoco, cuando está en la prisión y necesita de dinero, abogado, ropas, comida y demás". Se observa así que la criminalidad reproduce los patrones de género de la sociedad, así como en la vida real, las relaciones afectivas de mujeres con marido, hijo, padre y hermanos sugiere la sujeción de la mujer ante el otro, el deber de cuidado y aún, el deber de dar constantes pruebas de amor.

\section{Conclusión}

Históricamente, la óptica masculina de la legislación carcelaria planificada por hombres para hombres dejando de lado una legislación respecto a la población carcelaria femenina, en la actualidad el espacio mayoritario en cuanto a infraestructura es adecuado a una población masculina, en los últimos diez años se dio el crecimiento de la población carcelaria femenina en todo el ámbito de Latinoamérica, esto también responde al crecimiento del tráfico de drogas, soportando la opresión ante la falta de políticas de género en las prácticas jurídicas, actualmente se da la existencia de una falta de práctica y exposiciones legales nacionales e internacionales que se preocupen por las garantías de la mujer en situación de privación de libertad.

Teniendo como premisa el real funcionamiento del sistema penal en una sociedad capitalista, que reproduce desigualdades sociales, manteniendo las asimetrías y se hacen necesarios debates de género para eliminar la preservación

${ }^{28}$ Relacionamientos románticos son dinámicas de poder socialmente construidos pautados en apego excesivo, ciúmes, declaraciones de amor, etc. con el objetivo de manipulación y sometimiento de la mujer para el hombre. 
de las jerarquías, con los efectos mantener el status quo y la eliminación de los parámetros prefijados en cuanto a práctica social, sin tener en cuenta las características específicas de la mujer y la falta de perspectiva de género tanto en el aspecto normativo pero más centrándose en el aspecto práctico.

En ambos sistemas cabe recalcar que se debe dar un análisis más profundo procurando una mayor protección y la aplicación diferenciada en cuanto tratamiento de las mujeres respecto de los hombres, para la eliminación de estas barreras y coadyuvar a la mujer a no ser victimizada continuamente, tomando como base el análisis del hecho que originó su actividad delictual, evitando que se dé la cadena victimizante respecto de la mujer sin brindar la protección adecuada a la mujer que puede ser producto de la falta de infraestructura institucional o social que brinde apoyo para evitar se recurra a medios no lícitos, o que vuelvan a realizar a una conducta típica sobre el que recae una penalidad agravada.

Por eso, no se pueden dar aplicación a las mismas disposiciones para adecuar conductas masculinas, a la adecuada reinserción social de la prisión carcelaria femenina, en Brasil las mujeres negras pobres cumplen pena por el crimen de tráfico de drogas en la misma forma que los hombres, aunque hayan incurrido en un delito más graves los hombres, por ello es que no se debe desconocer la existencia de factores potenciadores que dan origen a la transgresión de las mujeres, y que mayoritariamente responde a una estructura de poder (dominante-dominado).

En Brasil el hecho de la existencia de una zanja racial es lo que favorece la reincidencia en la delincuencia, ante la falta de posibilidades de integrarse socialmente, por carencia de elementos que le permitan actuar en la vida social y la necesidad de no permanecer invisible frente a la falta de agrupamiento hace que se incorporen a un grupo en respuesta a esa necesidad de pertenencia.

En Argentina se circunscribe a la mujer que es víctima de la violencia que generalmente se ve obligada a realizar conductas delictivas, también responde al hecho de una cuestión no racial si no más social, por ende hay menos oportunidades frente a mujeres que no tienen una preparación educativa pre-exigida siendo cercenante a la hora de ingresar a un ámbito laboral, además de la situación muchas veces de ser la única sostén familiar y obedeciendo a diferentes presiones, la respuesta ante la atención de necesidades urgentes lleva generalmente a terminar cometiendo actividades ilícitas. A dicha problemática se suma la cuestión de la población extranjera que ingresa al país y que al no poder adecuarse a los cambios culturales o sobre todo el idioma, es más proclive a terminar siendo usadas como instrumentos dentro del trafico de drogas. 
Cuando se estudia la población carcelaria femenina es imposible no atenerse al análisis de factores potenciadores que lleva a que se dé la inmersión de los individuos en el ámbito criminal, dentro de estos conjuntos de factores podemos mencionar, la desigualdad social, racismo, desequilibrio económico, factores psicológicos, invisibilidad y necesidad de pertenencia, entre otras cuestiones.

\section{Bibliografía}

Avena, Norberto Cláudio Pâncaro. Execução Penal: esquematizado. 1. ed. São Paulo: Forense, 2014, p. 173.

Base de datos de SNEEP-Dirección Nacional De Política Criminal, Sistema Nacional de Estadísticas sobre Ejecución de la Pena, Informe Anual Servicio Penitenciario Federal, 2010 y Comisión de Cárceles de la Defensoría General de la Nación, Informe Anual 2010 a 2014.

Barcinski, Mariana. Mulheres no tráfico de drogas: a criminalidade como estratégia de saída da invisibilidade social feminina. PEPSIC.2012. Disponível em: [http://pepsic.bvsalud.org/scielo.php?script=sci_arttext\&pid $=\mathrm{S} 198334822012000100007 \mathrm{~J}$. Acesso em: 21 março 2016.

Castilho, Ela Wiecko V. de. E xecução da Pena Privativa de Liberdade para Mulheres: a Urgência de Regime Especial. Justitia, São Paulo, 64 (197). jul/dez. 2007.

Centro de Estudios Legales y Sociales (CELS), Ministerio Público de la Defensa de la Nación, Procuración Penitenciaria de la Nación, Mujeres en prisión: Los alcances del castigo, Buenos Aires, Siglo Veintiuno Editores, 2011.

Cornell Law School's Avon Global Center For Women And Justice And International Human Rights Clinic; Defensoría General de la Nación de la República Argentina; The University Of Chicago Law School International; Human Rights Clinic; "mujeres en prisión en Argentina: condiciones, causas y consecuencias". Mayo 2013.

Defensoría General de la Nación, Comisión de Cárceles, "Informe semestral enero/junio 2006", pp. 74-8.

Espinoza, Olga. A mulher como vítima e agressora no sistema punitivo. In:

Revista Transdisciplinar de Ciências Penitenciárias. Universidade Católica de Pelotas.V.2, N. 1 EDUCAT, 2003, p. 39.

Levantamento Nacional de Informações Penitenciárias. Infopen Mulheres Junho 
de 2014. Disponível em: [http://www.justica.gov.br/noticias/estudotracaperfildapopulacaopenitenciariafemininanobrasil/relatorioinfopenmulheres. pdf]. Acesso em: 24 de março 2016.

Levantamento Nacional de Informações Penitenciárias Infopen-Junho de 2014. Departamento Penitenciário Nacional.2014. Disponível em: [http://www. justica.gov.br/noticias/mjdivulgaranovorelatoriodoinfopennestatercafeira/ relatoriodepenversaoweb.pdf]. Acesso em: 17 março 2016.

Lopes J. R., Aury. Direito Processual Penal. 12a ed. São Paulo, Saraiva. 2015, p. 45.

Ministerio Público de la Defensa de la Nación, Procuración Penitenciaria de la Nación. "Mujeres en prisión: los alcances del castigo / compilado por CELS" $-1^{\mathrm{a}}$ ed.- Buenos Aires: Siglo Veintiuno Editores, 2011.

Regras das Nações Unidas para o tratamento de mulheres presas e medidas não privativas de liberdade para mulheres infratoras (Regras de Bangkok).

Sanchez, Marina N. "La mujer en la teoría criminológica". La ventana No 20. 2004.

Zaluar, A. Women of gangsters: Chronicle of a lessthanmusical city. Estudos Feministas, 1993, p. 181. 